DOI 10.37882/2223-2982.2021.09.01

\title{
ПРАГМАТИКА ЭМОЦИЙ В ИОРДАНСКОМ АКАДЕМИЧЕСКОМ ДИСКУРСЕ: НА ПРИМЕРЕ СОПОСТАВЛЕНИЯ РУССКОГО, ИОРДАНСКОГО И АМЕРИКАНСКОГО ДИСКУРСОВ
}

\section{PRAGMATICS OF EMOTIONS IN JORDANIAN ACADEMIC DISCOURSE: CASE STUDY OF COMPARISON OF RUSSIAN, JORDANIAN AND AMERICAN DISCOURSES}

Alhaded Hashem Hani Shehadeh

Summary: Jordanian academic discourse as a part of the Arab culture of the Middle East is distinguished by a set of certain ethnocultural features of emotional communication, the incorrect interpretation of which by foreign cultural participants in communication entails failures in intercultural interaction. The purpose of this article is to consider the main points and patterns of emotional communication of Jordanian academic discourse in higher educational universities of Amman, to characterize emotional restraint and openness in the Jordanian dialect of the Arabic language, and also to study the pragmatics of non-verbal emotional acts of Jordanian academic discourse. As illustrations, the article provides a comparison of the Russian-speaking, Anglo-Saxon and Arab cultures, but the main emphasis is placed on the Jordanian linguistic culture. In the article, we admitted a high degree of generalization, since our analysis is based on the ethnocultural level of communication. The material of the research was the data of empirical research obtained by the method of questioning and direct observation, theoretical sources. The results of the study showed that the pragmatics of emotions in the Jordanian academic discourse has its own ethnocultural specificity, which is characterized by certain functional and pragmatic features of emotional communication between student and teacher.

Keywords: Jordanian academic discourse, emotional communication, pragmatics of emotions.

\section{Введение}

$\mathrm{B}$ любой лингвокультуре эмоции играют одну из самых важных ролей при коммуникации, а также они могут как сплотить людей, так и послужить основой недопонимания между собеседниками. Эмоции можно разделить на три категории: универсальные, специфичные и индивидуальные. Базовые эмоции объединяют людей, причём такой вид эмоций присутствуют у каждой языковой личности без каких-либо культурных различий. [Шаховский 2008: 300]. Более того, по мнению В.И. Шаховского, эмоции не только делают людей разных культур похожими друг на друга, но и делают каждого из нас уникальным вследствие индивидуального варьиро-

\author{
Алхадед Хашем Хани Шехадех \\ аспирант, преподаватель, Российский университет \\ дружбы народов \\ hashem_1256@hotmail.com
}

Аннотация: Иорданский академический дискурс как часть арабской культуры Ближнего Востока отличается набором определённых этнокультурных особенностей эмоциональной коммуникации, неправильное интерпретация инокультурными участниками коммуникации которых влечёт за собой неудачи в межкультурном взаимодействии. Цель данной статьи - изучить основные моменты и закономерности эмоциональной коммуникации иорданцев в рамках академического дискурса в высших учебных заведениях Аммана, охарактеризовать эмоциональную сдержанность и открытость в иорданском диалекте арабского языка, а также изучить прагматику невербальных эмоциональных актов в рамках иорданского академического дискурса. В качестве иллюстраций в статье приводится сравнение русскоязычной, англосаксонской и арабской культур, однако основной акцент сделан на иорданскую лингвокультуру. В статье нами была допущена высокая степень генерализации, так как наш анализ строится на этнокультурном уровне коммуникации. Материалом исследования послужили данные эмпирических исследований, полученные методом анкетирования и непосредственного наблюдения, теоретические источники. Результаты исследования показали, что прагматика эмоций в иорданском академическом дискурсе имеет свою этнокультурную специфику, которой присуще определённые функционально-прагматические особенности эмоциональной коммуникации студентпреподаватель.

Ключевые слова: иорданский академический дискурс, эмоциональная коммуникация, прагматика эмоций.

вания базовых или других эмоций [Шаховский 2008: 300].

В данной работе нами был выбран этнокультурный уровень для рассмотрения некоторых закономерностей эмоциональной коммуникации в рамках иорданского академического дискурса. Так, Т.В. Ларина определяет этнокультурный стиль коммуникации как "исторически сложившийся, предопределяемый культурой и закреплённый традицией тип коммуникативного поведения народа, проявляющийся в выборе и предпочтительности определённых стратегий и средств коммуникации (вербальных и невербальных), используемых в процессе межличностного взаимодействия" [Ларина 2013: 196]. По нашему мнению, именно рассмотрение прагматики 
эмоций иорданского академического дискурса в рамках коммуникативного этностиля, или этнокультурного стиля коммуникации, позволит более детально рассмотреть отличительные черты иорданской культуры в рамках академического дискурса.

Изучение эмоциональной составляющей иорданского академического дискурса очень важная составляющая при межкультурном общении, особенно для не носителей арабского языка. Довольно часто непонимание иорданского эмоционального плана коммуникации носителями инокультур, к примеру, носителями русской, европейской, американской, азиатской культур, в рамках академического дискурса приводит к различным проблемам и сбоям коммуникации. Так как то, что в иорданском академическом дискурсе в плане выражения эмоций может быть дозволено и употребляться повсеместно, в европейской культуре или русской может быть воспринято как нарушение личных границ, неуважение, пренебрежение или грубость.

Отметим, что в ходе большого количества научных лингвистических работ авторы приходят к выводу о том, что одной из самых главных причин сбоев в коммуникации в рамках межкультурного контекста является различие в прагматике эмоциональных актов. Так, Т.В. Ларина отмечает, что именно игнорирование различий в прагматике эмоциональных актов приводит к "неадекватной интерпретации поведения инокультурного собеседника, его действий и эмоционального состояния" [Ларина 2015: 2]. Более того, если мы проведём сопоставительный анализ эмоциональной коммуникации в рамках разных академических дискурсах, то мы заметим, что один и тот же эмоциональный акт как вербальный, так и не вербальный может кардинально отличаться по своей прагматической направленности, а также может выполнять различные функции. Такие прагматические различия напрямую связаны со степенью эмоциональной открытости или эмоциональной сдержанности, связаны с отличительными вербальными и невербальными особенностями той или иной культуры, а также связаны с нормами эмоционального поведения, присущи той или иной культуре. Отметим, что также такие прагматические различия связаны со сферой социальных правил, принятых в рамках того или иного общества.

\section{Эмоциональная слеруканность/открытость в коммуникашии и в языке в иорАанском

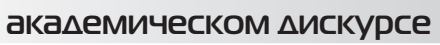

Как и любой другой стиль коммуникации в рамках той или иной культуры, иорданский стиль коммуникации между преподавателем и студентом отличается от американского или русского стиля степенью эмоциональной поведения: сдержанности или открытости, контролируемости или неконтролируемости, эксплицитности или имплицитности. Каждый народ имеет свои культурно и социально обусловленные правила проявления эмоций. Так, у англичан, эстонцев, японцев и китайцев самоконтроль, сдержанность и чрезвычайно минимальное проявление эмоций является образцом эмоционального проявления не только в рамках их академических дискурсов, но и в культурах в целом. В то время как латиноамериканцы, арабы, иранцы отличаются своей экспрессивностью выражения и обилием невербальных знаков общения. К примеру, арабы в целом и иорданцы в частности при общении используют повышенный тон, делают паузы перед самыми важными фразами в их речи, тем самым привлекая к ним внимание слушателей. Более того представители арабских культур, причём как исповедующие Ислам, так и христианство различных течений, активно используют в речи такие клятвы, как "وله" ("ва Аллахи"), что обозначается "клянусь Богом". Интересно, что при использовании таких клятв араб не вкладывает в это смысл клятвы, то есть на прагматическом уровне это больше похоже на русское выражение "честное слово".

Также для арабов в речи очень важно использование фраз, которые будут переведены на русский язык с оттеночным религиозным значением, хотя на практике в иорданской коммуникативной культуре эти фразы используются для украшения речи и большей экспрессивности. К таких фразам мы можем отнести "الحمد الله" (Аль хамду ли Ля) - "слава Богу", "سبحان الله" (субхан Алла) - "спасибо Богу" (именно за что-то), "استغفر الله" (истагфар Алла) - "Боже мой" (используется в

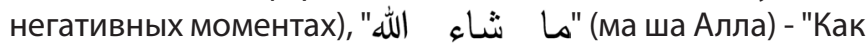
пожелает Бог" (используется при позитивных, радостных моментах), "خله خبر" (ляалю хейр) - "будь, что будет" и т.д. Как считают многие лингвисты-востоковеды, важный момент иорданской степени эмоциональной открытости - гендерное различие. Хотим заметить, что в последнее время иорданская женщина намного сильнее укрепила своё положение в обществе, в связи с этим на данный момент мы настаиваем на том, что эмоциональное поведение не может быть присуще только иорданскому мужчине, экспрессивность выражения мыслей как в иорданской культуре, так и в иорданском академическом дискурсе свойственна и арабской женщине.

Отметим, что в эмоциональной открытости представителей иорданского академического дискурса большую роль играют определённые грамматические конструкции, используемые в речи, в общении между преподавателем и студентом. Так, отличительной особенностью является дублирование слов во фразе, что при переводе на другие языки опускается или переводчиком применяется один из методов лексико-грамматической трансформации, так как фраза не несёт в себе никакого прагматического смысла, однако в то же время очень важно для иорданского стиля коммуникации. 
Примерами таких фраз могут послужить "كتب كتاباً", что в дословном переводе означает "писать письмом", на русский такая фраза скорее переведётся глаголом "писать". Из личного опыта можно привести ряд предложений, которые часто употребляются в рамках аудитории или в процессе коммуникации студент-преподаватель в Иордании.

$$
\text { 1. يا أحمد, أكتب كتاباً كلمات جديدة على السبورة }
$$

Если мы переведем дословно данное предложение, то получим следующее: "Ахмад, напиши письмом [используется отглагольное существительно от глагола "писать"] новые слова на доске". При адекватном переводе на русском языке мы опустим дублирование "напиши письмом" и переведём следующим образом: "Ахмад, напиши новые слова на доске". Что касается эмоциональной окраски данного утверждения, то она носит приказной тон, который характерен для иорданского академического дискурса.

$$
\text { 2. ما عملت شيء, بس جلس جلوساً في الصيف خلال الدرس. }
$$

Я ничего такого не делал, просто сидел сиденьем в аудитории во время занятия.

$$
\text { 3.طلابي، أنا رسل رسالةً الوجب المنزلي عبر الميل. }
$$

Студенты, я отправил(а) отправлением домашнее задание по е-mail.

$$
\text { 4.صر احة امبار ح درسنا در اساً طول اليل. }
$$

честно, вчера учились учёбой всю ночь.

Пронаблюдав частоту и цель использования подобных уподоблений арабских конструкций, где первое слово выражено глаголом, а второе отглагольным существительным в форме единственного числа, неопределённого состояния, мы пришли к выводу о том, что подобное удвоение в контексте иорданского академического дискурса используется с целью акцентирования говорящим внимания служащего на том действии, которое было совершено первым. Отметим, что подобно нагромождение характерно для жителей стран Леванта и Севера Африки.

Однако мы не может утверждать, что в иорданском академическом дискурсе полностью отсутствует эмоциональная сдержанность. Для того, чтобы лучше понять ключевые особенности эмоциональной сдержанности иорданцев, приведём сопоставительный анализ сдержанности в американской и русской культурах. Так, для англосаксонской культуры проявление негативных эмоций - грусть, печаль, скорбь, уныние, злость - является не приемлемым, так как это воспринимается в обществе как незрелость и невоспитанность человека [Ларина 2015: 3]. Интересно, как представители американской культуры расценивают сдержанность и возможность "утаить" от всех свои настоящие эмоции как заслугу: "for having shown such control and restraint" [Виссон 2003: 181]. Подобное скрытие своих эмоций от публики будет расценено с точки зрения как араба, так и русского как фальшь, игра на публику и неискренность человека в своих эмоциях. Отметим, что особый стиль поведения представителя англосаксонской лингвокультуры в тяжёлых жизненных ситуациях является предметом изучения многих российских и западных учёных (Карасик 2002; Ларина 2009, 2013, 2015; Джиоева, Соседова 2014, Fox 2005, Amr A A Khalil 2018). Более того, для американца или для любого представителя англосаксонской культуры демонстрирование бодрого духа, оптимизма и хорошего настроения является одним из основополагающих моментов в поведении. Так, "be optimistic" ("будь оптимистом") - одна из основных стратегий английской вежливости, стратегий, которые были выведены и названы П. Браун и С. Левинсоном в их хрестоматийной монографии [Brown, Levinson 1987]. Что касается представителя русской лингвокультуры, проявление эмоций не воспринимается обществом как нечто табуированное, нарушающее их личностные границы или заводящее окружающих в тупик. Так, по мнению А. Вежбицкой, русская культура - это когда "хорошо, что другие люди знают, что человек чувствует" [Вежбицкая 1999:141]. Для русского человека проявлять свои эмоции является естественным моментом, однако в последнее время мы можем наблюдать тот факт, что жители больших русских городов таких как, Москва, Санкт-Петербург, Сочи, скорее негативно отнесутся к проявлению каких-либо эмоций человеком, с которым они недостаточно хорошо знакомы. Более того, мы можем наблюдать изменения в отношении того, как житель русского мегаполиса расценивает фразу "отдаваться чувству", "повиноваться чувству". Полагаем, что жителем русского города-миллионника эти фразы стали восприниматься в негативном контексте, так как это обозначает, что человек осознано/неосознанно забывает о своей рассудочности и расчётливости. Напротив же, для небольших городов в России излишне расчётливый человек представляется в негативном свете. Однако в контексте русской лингвокультуры "находится во власти эмоций" так же, как и "действовать под влиянием эмоций" является негативным аспектом проявления эмоций и расценивается отрицательно [Шмелев 2002: 319].

Что касается иорданской эмоциональной сдержанности, то в силу устоявшихся традиций и обычаев, при которых слово старшего в независимости от того, является ли он тебе родственником или незнакомцем, является главным, существует определённый набор обращений, грамматических конструкций, а также способов вербального общения, являющихся признаками эмоциональной сдержанности. Для того, чтобы пронаблюдать эмоциональную сдержанность в иорданском академическом дискурсе нами было проведено анкетирование, 
состоящее из вопросов-ситуаций, на которые иорданскому студенту следовало написать то, как бы он повел/ ведет себя и что бы сказал/говорит преподаватель в данных ситуациях. Так, на ситуацию "обратитесь к преподавателю в классе с целью уточнения информации", большинство студентов указали такие арабские обращения, как "الدكتور" (ад-дуктур) (см. пример 5), где слово "дуктур" употребляется в отношении преподавателей, которые имеют PhD степень), "الدكتورة" (ад-дуктура), (см. пример 6), употребляется при обращении студента к профессору/преподавателю женщине с учёной степенью; "الكعلَّ" (аль-муалим), (см. пример 7), употребляется по отношению к преподавателям, которые долгое время преподают, однако не имеют учёной степени $\mathrm{PhD}$, "المعلمة" (аль-муалима), (см, пример 8), так же, как и пример 7, употребляется при обращении к женщине преподавательнице, и реже в ответах респондентов можно было встретить обращения "استاذ" (устаз), "استاذة" (устаза) (см. пример 9), так как такая форма обращения может быть использована только по отношению к студентам старших курсов, которые преподают студентам младших курсов в качестве педагогической практики, а также к молодым преподавателям без учёной степени и без опыта работы.

$$
\text { 5. الدكتور محمد انا نسيت هذا الموضوع ممكن نعيده؟ }
$$

Доктор Мухаммад, я забыл эту тему, мы можем вернуться к ее повторению?

$$
\text { 6.الدكتورة جميل احنا ما فهنا هابي النقطة }
$$

Доктора Джамиля, мы не поняли этот момент.

$$
\text { 7.المعلم انا ما بتذكر هاد }
$$

Учитель, я этого не помню.

$$
\text { 8.المعلمة هل من الممكن نعمل المر اجعة؟ }
$$

Учительница, а можем ли мы пройти это заново?

$$
\text { 9.استاذة عبير انا ما فهمتك }
$$

Учительница Абир, я вас не понял.

Подобные обращения являются признаками иорданской эмоциональной сдержанности, так как любое из обращений свидетельствует об уважении студента к преподавателю. Интересно также пронаблюдать, способы выражения иорданской эмоциональной сдержанности В рамках обращения преподавателя к студенту. В силу того, что преподавателя в Иордании в меньшей степени обременяют рамки употребления определённых обращений по отношению к студентам, мы можем выделить В некоторой степени больше примеров обращений: "السبد/السبدة" (ассейд, ассейда) (см. пример 10), является деловым стилем обращения, использование которого является ярким примером эмоциональной сдержанности иорданцев; "صديق/صديقة" (садык, садыка) (см. пример
11), "المحترم/المحترمة" (аль-мухтарим, аль-мухтарима) (см.

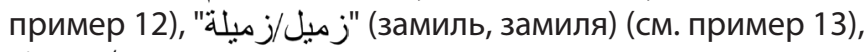
"عزيز/عزيزة" (азиз, азиза) (см. пример 13), а также преподаватель может обратиться к студенту, с кем у них есть взаимопонимание и доверие, используя более неформальный тип обращений - "عمي/عود" (амми, аммо) (см. пример 14), "خله/خلتي" (халу, хальти) (см. пример 15).

$$
\text { 10.السبد جمال تفضل الى السبورة }
$$

Господин Джамаль, прошу вас пройти к доске.

$$
\text { 11.صديقي أعطيني هاد الدفتر }
$$

Друг мой, а дай-ка мне эту тетрадь

$$
\text { 12.احمد المحترم ليش متاخر؟ }
$$

Уважаемый Ахмад, почему вы опоздали?

$$
\text { 13.عزيزني وين الواجب المنزلي؟ }
$$

Дорогая моя, а где домашнее задание?

$$
\text { 14.وين عمو غايب؟ }
$$

Друг, ну и где же ты пропадаешь?

Приятель, ты выглядишь больным

$$
\text { 15.خله انت شكلك مريض }
$$

Таким образом, для иорданской лингвокультуры в целом характерно проявления широкого спектра эмоций как в аудитории, так и вне университета, однако нарушение определённых правил поведения может повлечь недопонимание. К примеру, если студент или преподаватель будет громко смеяться в аудитории или на улице, это будет воспринято как вызывающее, вульгарное поведение. Злость, крик, агрессия по стороны преподавателя будут восприняты студентами скорее нейтрально, чем негативно, так как выражение негативных эмоций присуще всему арабоязычному миру.

\section{Прагматика вербальных и невербальных эмоциональных актов в иорАанском

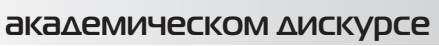

Невербальные (поза, улыбка, слезы, взгляд) и паравербальные (интонация, громкость, тембр голоса, молчание) знаки эмоциональной коммуникации в иорданской лингвокультуре обладают определённой этнокультурной спецификой, которая может быть либо не понята, либо понята неправильно представителями других культур.

Однако удивительным является тот факт, что американцы, которые склонны к сдерживанию своих эмоций, в вербальной коммуникации демонстрируют высокий уровень эмоциональной экспрессивности [Ларина 2003, 2009, 2015 и др.]. Так, в различных ситуациях представи- 
тель англосаксонской культуры дает завышенную оценку всему происходящему и самому собеседнику, применяя большой спектр эмоционально окрашенных лексем: great, perfect, gorgeous, wonderful, superb, fabulous, marvelous. Как пишет Т. Ларина, подобные лексемы "нацелены не столько на передачу информации об эмоциональном состоянии говорящего, сколько на передачу позитивного отношения к собеседнику, на оказание ему коммуникативной поддержки" [Ларина 2015: 7]. Если мы сравним иорданскую лингвокультуру и американскую в отношении вербальной эмоциональной экспрессивности, то увидим некоторую схожесть. Примечательно, что в преподаватель в университете употребляет такие выражения, как "رائع" (раиа) (в пер. "идеально"), "احسنت (ахсант) (в пер. "молодец"), "ثناطر" (шатыр) (в пер. успешный), "مزبوط" (мумтаз) (в пер. "превосходно"), "معتاز" (мазбут) (в пер. "именно так"), с той же самой целью, т.е. с целью показать студенту, что он настроен к нему позитивно и намерен оказывать коммуникативную поддержку.

Так, если в американской или русской лингвокультурах прямой взгляд студента в глаза преподавателя означает уважение и внимание, то в рамках иорданской лингвокультуры прямой взгляд в глаза преподавателю обозначает невежество студента, вызов и неуважение. Что касается такого эмоционального знака, как улыбка, то в иорданском академическом дискурсе прагматическая интенция улыбающегося студента/преподавателя будет расценена негативно. Тер-Минасова выделяет три типа улыбки: искренняя, коммерческая и формальная [Тер-Минасова 2000: 193]. Однозначно, в целом в иорданской лингвокультуре встречается все типы улыбок, однако в рамках иорданского академического дискурса улыбка является признаком неуважения к говорящему, признаком "заигрования" в говорящим, что непозволительно в рамках академического дискурса в Иордании.

Что касается паравербальных знаков эмоциональной коммуникации иорданцев в рамках академического дискурса, то использование пауз при выступлении перед аудиторией/публикой и высокая громкость голоса преподавателя при общении со студентами или объявлении нового материала являются неотъемлемой частью эмотивного плана коммуникации иорданцев. Более того, такой паравербальный знак эмоциональной коммуникации как молчание также широко использует- ся преподавателем для того, чтобы выразить озабоченность или недовольство студентом/группой. Иорданскими студентами также часто используется молчание для выражения согласия с преподавателем.

Таким образом, мы видим, что иорданский академически дискурс отличается определёнными особенностями вербального и невербального поведения студента и преподавателя, непонимание прагматических особенностей которых ведет к коммуникативным неудачам.

\section{ЗакАючение}

В данной статье было показано, что прагматика эмоций в иорданском академическом дискурсе имеет свою этнокультурную специфику, которой присуще определённые функционально-прагматические особенности эмоциональной коммуникации студент-преподаватель. Сопоставительный анализ иорданской лингвокультуры в контексте академического дискурса с американской и русской лингвокультурами показал, что прагматический аспект эмоциональной коммуникации иорданцев более экспрессивен, импульсивен.

Таким образом, мы пришли к выводу о том, что эмоциональная сдержанность в иорданском диалекте арабского языка сопровождается употреблением определённых грамматических форм и форм обращений. В свою очередь эмоциональная открытость иорданцев в рамках университета выражается в активном использовании вербальной эмоциональной экспрессивности, что также характерно и для американской лингвокультуры. На невербальном и паравербальном уровнях коммуникации в рамках иорданского академического дискурса существует определённая система употребления коммуникативных знаков, к примеру, прямой взгляд в глаза вызов, улыбка - признак невежества, паузы - средство привлечение внимание, молчание - выражение преподавателем гнева или несогласия. Незнание или неправильная интерпретация данной системы знаков влечёт за собой к коммуникативным неудачам.

Изложенные нами идеи в данной статье могут стать основой для дальнейших сопоставительных исследований с привлечением других культур и языков, что позволит сделать исследования в данной области более глубокими.

\section{ЛИТЕРАТУРА}

1. Вежбицкая А. Семантические универсалии и описание языков / Пер. с англ. А.Д. Шмелева; под ред. Т.В. Булыгиной. М.: Языки русской культуры, 1999. C. $503-546$.

2. Вежбицкая А. Язык. Культура. Познание. М.: Русские словари, 1997. 410 с.

3. Виссон Л. Русские проблемы в английской речи. Слова и фразы в контексте двух культур. Пер. с англ. М.: Р. Валент, 2003. 
4. Ларина Т.В. Англичане и русские: язык, культура, коммуникация. М.: Языки славянских культур, 2013.

5. Ларина Т.В. Категория вежливости в английской и русской коммуникативных культурах. М.: Изд-во РУдН, 2003.

6. Ларина Татьяна Викторовна Прагматика эмоций в межкультурном контексте // Вестник РудН. Серия: Лингвистика. 2015 . №1.

7. Тер-Минасова С.Г. Язык и межкультурная коммуникация. М.: Слово, 2000.

8. Шаховский В.И. Лингвистическая теория эмоций. М.: Гнозис, 2008.

9. Шмелев А.Д. Русская языковая модель мира. Опыт словаря. М.: Языки славянских культур, 2002.319 с.

10. Brown P. and Stephen D. Levinson. Politeness: Some universals in language usage. Cambridge: Cambridge University Press, 1987.

\section{() Алхадед Хашем Хани Шехадех (hashem_1256@hotmail.com).}

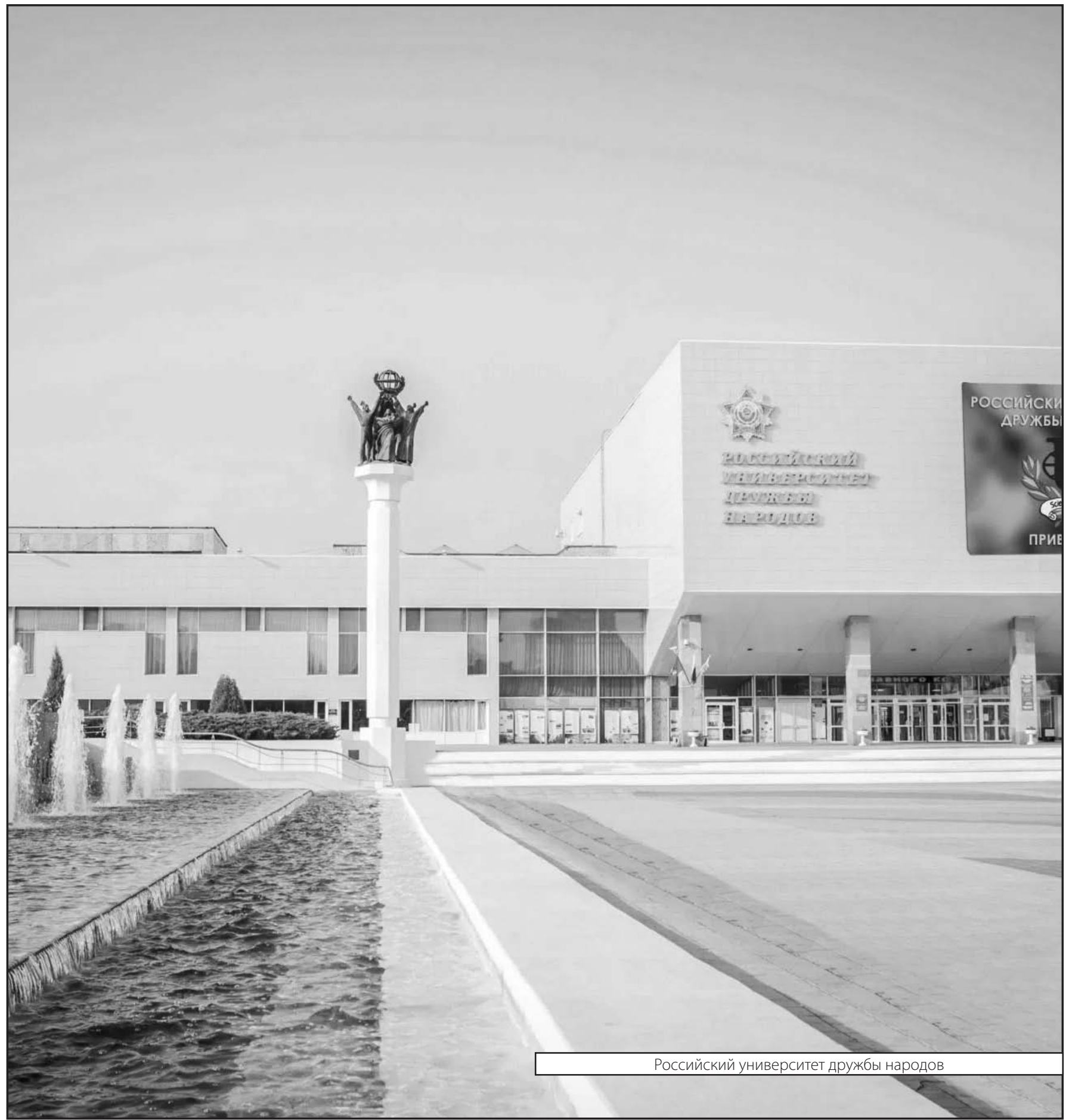

